\title{
An Experimental Analysis of Harmonic Distortion Indices In Home Based Electrical Appliances and Improvement Using Passive Filter
}

\author{
Muhammad Shahzad Bajwa ${ }^{1, *}$, Muhammad Usman Keerio ${ }^{1}$, Mohsin Ali Koondhar ${ }^{1}$, Noor Hussain \\ Mugheri $^{1}$, Irfan Ali Channa ${ }^{2}$ \\ ${ }^{1}$ Department of Electrical Engineering, QUEST, Nawabshah, Pakistan \\ ${ }^{2}$ Department of Automation, Beijing University of Chemical Technology, Beijing, China \\ ${ }^{*}$ Corresponding author: shahzadbajwa@quest.edu.pk
}

\begin{abstract}
Nowadays, the growing use of non-linear loads in home appliances gives rise to harmonic pollution in the electrical power distribution system, which degrades the power quality. Many domestic appliances have power electronic converters that characteristically draw a non-sinusoidal current waveform. Short-term effects of non-linear appliances are causing malfunction and damage of electronic devices and long-term effects are thermal losses in equipment and cable, hasty aging, and reduced life period of devices. The whole impact depends on the power ratings and quantity of electrical appliances and their harmonic diversity. Usually, the existence of harmonics and their effects in a domestic zone are not monitored as compared to the industrial and commercial sectors. To ensure the quality of power, it is necessary that a harmonic study is carried out to identify the details of harmonic pollution that is polluting sources, the parameters or quantities they pollute in each instance, and effective improvement methods. In this paper, experimental analysis was performed which focuses on traditional single-phase home-based electrical appliances causing the quality of power down, and implementation of the passive filter is suggested for improvement in the quality of power. All experimental harmonic distortion measurements of home-based electrical appliances were performed in the power electronic laboratory of QUEST Nawabshah. Harmonic distortion indices measurements of home-based electrical appliances have been taken using the fluke power quality Analyzer (PQA) instrument. The analysis shows that from many types of loads, switch mode power supply (SMPS) based load is rich in harmonic distortion. Therefore, an equivalent model of SMPS load in MATLAB/Simulink is developed to analyze improvement in power quality by designing and implementation of the passive filter. The outcome of this research work will be helpful to make the source current sinusoidal by reducing harmonic distortion and thus improve the power quality.
\end{abstract}

Keywords-Home-based electrical appliances, Harmonics, Power factor, Power Quality Analyzer, Passive Filter.

\section{Introduction}

$\mathrm{T}$ HE Power quality (PQ) is the regulation in power for voltage, current, and frequency to keep these parameters under limits. The change occurs in voltage, current, and frequency from its constant magnitude and perfect sinusoidal waveform can cause a malfunction in every sensitive electric appliance [1]. During the past decade, important changes occur in electrical appliances comprising the domestic load. Modern electrical appliances which are based on power electronics technology are highly sensitive to power quality (PQ) issues [2]. Increasing power electronics devices in the

ISSN: 2523-0379 (Online), ISSN: 1605-8607 (Print)

DOI: https://doi.org/10.52584/QRJ.1901.18

This is an open access article published by Quaid-e-Awam University of Engineering Science 85 Technology, Nawabshah, Pakistan under CC BY 4.0 International License. electrical distribution systems, the increase of the harmonic distortion in the AC supply mains has become the main concern because of undesirable effects on all devices. Crucially, the proper actions should be taken to mitigate this problematic issue [3].

If the power quality of the electrical distribution system is good, then any connected electrical appliances will operate efficiently and smoothly. On the another hand, poor power quality causes malfunctioning of devices and damage [4]. The electrical installations may suffer from operational inefficiency, massive economic losses, system downtime, inaccuracy in measuring meters, deterioration in the power factor, reduction in life of the equipment, and high installation running costs [5].

Many studies cover the power quality problems 
caused by nonlinear loads and the mitigation solutions [6][18]. It is found in the measurements process that the harmonic distortion are produced in the time range of 12 to 14 hours and 20 to 22 hours due to home nonlinear electric appliances [19]. In residential places, the increase of solid-state switching devices has increased the harmonic levels. At present, power quality becomes an important issue for utilities as well as for customers [20]. As nonlinear load is increasing in electrical power systems, it requires more analysis on the harms related to harmonic distortion in the electrical system for devising solutions.

This research paper is structured as follows. The introduction of harmonic distortion and its effects are presented in Section 1. Section 2 presents various harmonic distortion indices. Section 3 gives categories of different loads. Section 4 shows measurement results of harmonics indices for various electrical appliances that are connected to the AC supply mains individually. Section 5 presents the simulated results of harmonic distortion mitigation by passive harmonic filter using MATLAB. Finally, Section 6 concludes the paper.

\section{Harmonic Distortion Indices}

Steady-state variation in voltage or current wave shape from its perfect sinusoidal wave of fundamental frequency (usually $50 \mathrm{~Hz}$ ) is called harmonic distortion. Harmonics comprises different frequencies with different wave shapes which are usually an integral multiple of fundamental frequency [21]. Harmonics are known since the development of the first $\mathrm{AC}$ power system. The harmonic investigation is the method of manipulating the magnitudes and phases in fundamental components and upper-order harmonics of the power system. Fourier analysis is applied to obtain the magnitude and frequency of the distorted waveform. The harmonic content in the distorted waves declines inversely with the increasing frequency. For estimating and analysis of the harmonic distortion, usually the indices mentioned in [22][23 are applied.

\subsection{Current and Voltage Harmonics}

Mathematically,

$$
I_{H}=\frac{I_{n}}{I_{1}}
$$

where $I_{H}$ is the value of harmonic current, $I_{n}$ is the value of nth harmonic current and $I_{1}$ is the fundamental value in the current waveform. $I$ can be changed with $V$ for the harmonic voltage.

\subsection{Total Harmonic Distortion}

Current waveforms is referred to as total harmonic distortion (THD) and is frequently written in percentage form. $T H D_{v}$ indicates total distortion in voltage waveform and $T H D_{i}$ indicates total distortion in the current waveform.

$$
T H D_{i}=\sqrt{\frac{\sum_{n=2}^{\infty} I_{(r m s, n)}^{2}}{I_{1}}}
$$

If $T H D_{i}$ is larger than $100 \%$, it means that harmonic component has more energy than the fundamental component.

\subsection{Cost Factor}

One of the simplest measures of distortion in the waveform is the relation between the peak value of a current signal and its RMS value is called crest factor $(\mathrm{CF})$.

$$
C F=\frac{I_{p e a k}}{I_{r m s}}
$$

In an ideal sinusoidal signal, the crest factor value is $C F=\sqrt{2}=1.4142$, while triangular wave shape would have high $C F$ and trapezoidal wave shape have lower $C F$.

\subsection{Displacement Power Factor}

The cosine of phase angle among the voltage and current in fundamental components is called displacement power factor (DPF). It is used to measure the efficiency that how much a load is using energy. This definition is applicable only in the case of voltage and current signals are sinusoidal.

$$
D P F=\operatorname{Cos} \phi=\frac{P}{S}
$$

The displacement power factor determines the loss of power caused by the phase difference. If the phase difference is high then the displacement power factor will be low and cause less amount of the apparent power $(S)$ delivered will be useful for a working power $(P)$ and a large amount of reactive power $(Q)$.

In a power system, to transfer the same amount of useful power, a load with a high power factor draws less current than a load with a low power factor and as a result has better efficiency. The intention behind the method of displacement power factor improvement is to decrease or compensate for the reactive power. When the displacement power factor is improved, it is possible that active power is nearly equal to apparent power and reactive power is reduced or approaches zero. The most familiar way for improvement of displacement power factor is connecting a capacitive 
element in parallel with the inductive load whose displacement power factor is low and required to be improved, but that method is efficient for inductive load.

\subsection{True Power Factor}

The True Power Factor (TPF) is that factor that is affected as a result of harmonic distortion or unbalances that occurred. The value of the true power factor is worse with an increasing phase angle between voltage and current and with increasing distortion in voltage or current signal. This definition includes both the phase angle and the wave shape distortion. Inadequate value of TPF raises power losses. Because in the case of harmonic loads no uniform phase shift angle can be specified, the often-used displacement power factor ( cost $\phi)$ and true power factor should not be equated. Therefore in that situation, the true power factor term must be used as,

$$
T P F=\operatorname{Cos} \phi * \frac{1}{\sqrt{1+T H D_{V}^{2}}} * \frac{1}{\sqrt{1+T H D_{I}^{2}}}
$$

\section{Load Categories}

As the variety of the load that is used in the electrical distribution system is increased, load effects are required to be investigated [24]. The household electrical devices are used a number of times per day which clearly shows their effects on the power system. A typical home has dozens of electrical appliances used commonly that are generally categorized as,

1) Resistive Load

2) Inductive Load

3) Switch Mode Power SupplyLoad

\subsection{Resistive Load}

Loads that have some kind of heating component are said to be resistive. If a load draws sinusoidal current waveform in the identical phase as the voltage waveform, i.e., the maximum, minimum, and zero points of both sinusoidal voltage and current waves align, that load is treated as resistive. The resistive load electrical appliances can be further divided into working principles based on lightning and heating. Lightning appliances are such that incandescent bulbs and heating appliances are such that iron, kettle, heater, toasters, coffee makers, etc. are the common examples of resistive loads that are used in homes.

\subsection{Inductive Load}

The primary component of the inductive load is the $\mathrm{AC}$ motors. If a load draws a current that reaches peak position after the voltage, and the current waveform lags the voltage waveform, then the load is said to be inductive. Inductive loads include water pump motor, juicer machine, pedestal fan, washing machine, refrigerator, speaker, vacuum cleaners, dishwashers, etc. In inductive load, the magnetizing current has harmonic content and is, therefore a source of harmonics. When the inductive load is connected to the electric supply or in running condition then the input supply current has a phase difference with the input supply voltage which causes a low power factor.

\subsection{Switch Mode Power Supply Load}

Any load that draws badly non-sinusoidal current waveform is because of the switch mode power supply contained in the circuitry of electrical appliances. When SMPS load is connected in AC electrical power distribution system, the current waveform is distorted and distorted current flow back to input supply causes distortion in the voltage waveform. The name of SMPS is so called because the switching occurs in a dc-to-dc converter intended for the change of the unregulated input dc voltage to a regulated output dc voltage. SMPS-based devices are in low power ratings which is the reason why they serve as energy-saving devices and enhance the electrical energy supply. Modern electrical appliances almost universally use SMPS to work with a broad range of input voltage and to minimize the wasted energy produced during the switching action between a full-on and full-off condition. SMPS loads can be a personal computer, laptop, LED TV, fluorescent lights, energy savor, UPS, battery charger, printer, etc.

\section{Analysis of Experimental Measurements}

To mitigate the harmonics, we must know the significant magnitudes of individual current and voltage harmonics. Experimental harmonic distortion measurement is performed to confirm or verify the degree of the severity level of distorted current and voltage waveforms during the operation of the domestic load. In an experimental study, measured results are obtained by an instrument called power quality analyzer (PQA) fluke 43B.

Harmonic distortion measurements have been conducted in a power electronic laboratory of the electrical department QUEST Nawabshah where all electrical appliances are collected and connected in isolate mode to find the details of harmonic polluting sources. The 
obtained results and graphical waveform are analyzed to overcome the issue of poor power quality and improvement purpose caused by harmonic distortion. The experimentally measured results for each category of load and individual electrical appliances measurements details are listed in Table 1.

\subsection{Resistive Load}

From mentioned experimental results, it is clear that resistive loads do not produce any significant harmonic distortion. Both input supply voltage and input supply current waveforms are in the sinusoidal form that's why these loads are also called linear loads. The Fast Fourier Transform (FFT) analysis of voltage and current waveforms shows only fundamental components having $50 \mathrm{~Hz}$ frequency. The values of the crest factor for both input supply voltage and input supply current waveforms are 1.4 which represents the sinusoidal waveforms. Since both mentioned waveforms are sinusoidal as well as in phase, therefore, both true power factor and displacement power factor have the same value of unity. However, the up and down from permissible rated voltage amplitude is affected to the performance of resistive load. In a broad sense, the power usage of the resistive load is like a "step", because in power-on state, it experiences a preliminary higher power usage. After this, it decays slowly to a relatively stable usage that remains stable. This preliminary higher power is owing to huge inrush (surge) current produced until the appliance warms up and decreases of resistance occur, subsequently it stabilizes.

\subsection{Inductive Load}

It is observed that unlike the results obtained from re-sistive loads mentioned above, almost all inductive loads have a brief, but significant early power usage. The result is that a surge occurs because of an inrush current flowing during starting stage of the AC motor. Usually, it is much greater than from heating elements, because the heat up process for heating element occurs slowly, the rotor enclosed by a motor necessarily move from a fully idle state to full speed state within seconds. Afterward, the motor's operation decides either a decay or growth that finally stabilizes. Unlike resistive loads, motors reveal little variations still for the duration of this "stable" period. For example when measurements have been taken for refrigerator appliance then a tiny fluctuation is seen which repeats throughout every compressor's cycle until usage stabilizes. This pattern illustrates that, unlike resistive

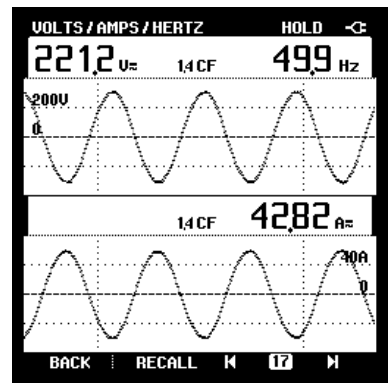

(a)

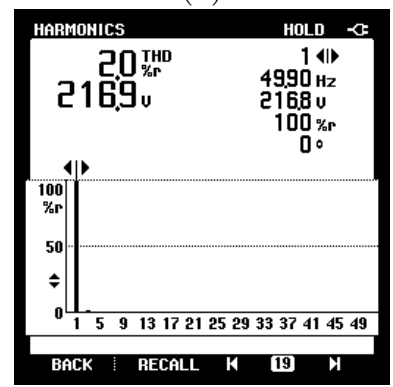

(c)

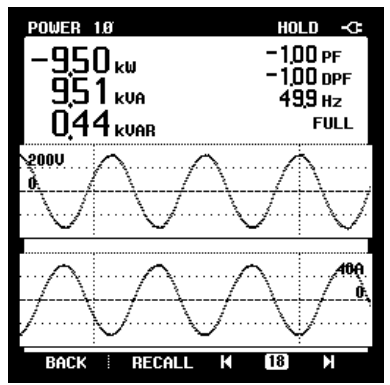

(b)

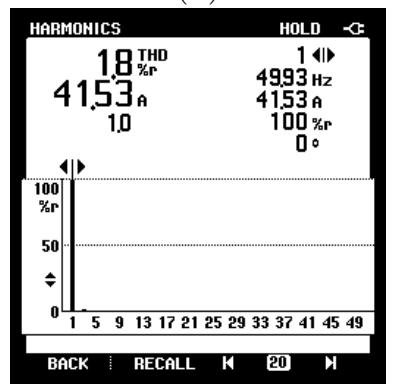

(d)
Fig. 1: Resisitive load, (a) Voltage \& Current Waveforms, (b) Power Quantities, (c) $T H D_{v}$, (d) $T H D_{i}$

loads, inductive loads modeling via easy on-off and step functions is challenging.

In inductive load, there is a phase difference $\mathrm{b} / \mathrm{w}$ fundamental harmonic components of voltage and current and they are out of phase. Due to this, current will lag behind applied voltage and the power factor will be of low value in the range of about $0.29-0.73$. This indicates a greater reactive power consumption and relatively low harmonic current distortion. Input supply current has high harmonic distortion with a significant contribution of 3rd and 5th order harmonics.

\subsection{Switch Mode Power Supply (SMPS) Load}

It is observed from the measured result that input supply voltage has an almost sinusoidal waveform as also indicated by crest factor which is nearly 1.4 resembling a sinusoidal waveform. Whereas, input supply current has the non-sinusoidal shape of the waveform as indicated by crest factor value which is higher from 1.4 value and shows that there are high distortions in the current waveform. Therefore, SMPS loads are rich in harmonic distortion.

It is seen from results that active power of most of power electronic loads is smaller as compared to resistive or linear load, therefore, this is the advantage related to electrical energy saving, but the reactive power drawn by the power electronic load is much 


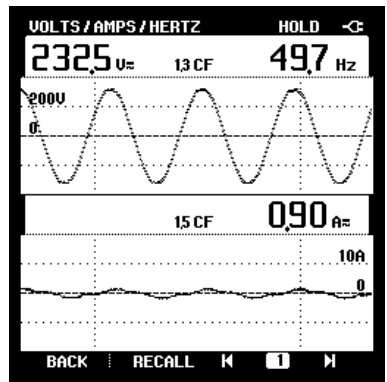

(a)

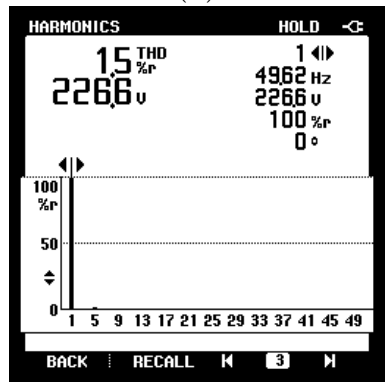

(c)

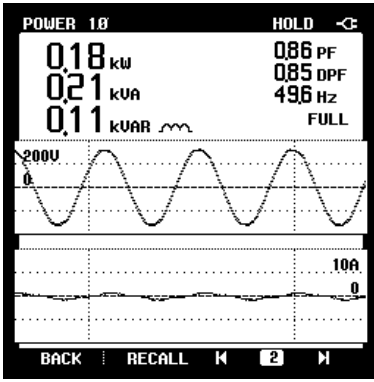

(b)

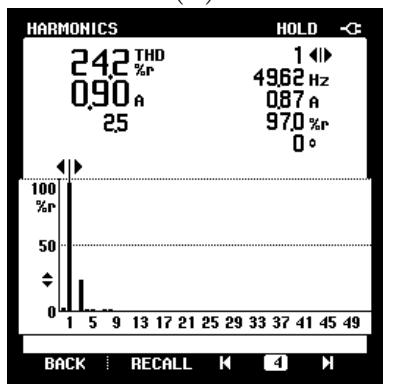

(d)

Fig. 2: Inductive load, (a) Voltage \& Current Waveforms, (b) Power Quantities, (c) THD $D_{v}$, (d) THD

higher than active power value which indicates harmonic distortion present in the loads causing a waste of apparent power delivered to the load. This type of load shows large power fluctuations in active period due to displaying and performing a variety of works. The measurements of microwave appliance initially look like a simple step which is analogous to the resistive loads. However, when working modes of the microwave oven were checked, it is observed that small and rapid variations occur in one minute from second to second period with bigger cyclic power shifts. Similarly, hairdryer shows distinct heat properties during their active region. Therefore, this type of load cannot be expressed simply like on-off models. Switch mode power supply based loads reveal different behavior in different parts of their cycle which largely depends upon which components of the appliance are in active stage. It is noticed from Table 1 that power electronic load has a high DPF (cos $\psi$ ) that is close to 0.9 , but a bad true power factor value which lies in the range of 0.3-0.7. If there is a large difference between the value of DPF and TPF, it represents a highly distorted current drawn by power electronic load. Now DPF $(\cos \phi)$ will be worthless because it is only applied for fundamental power, while True Power Factor (TPF) includes the entire harmonics in the waveform.

For SMPS load, more focus should be given on improvement in true power factor (TPF) rather than on displacement power factor. Based on the FFT

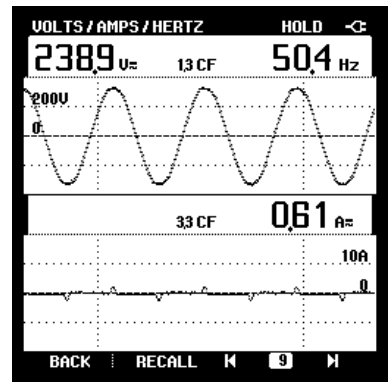

(a)

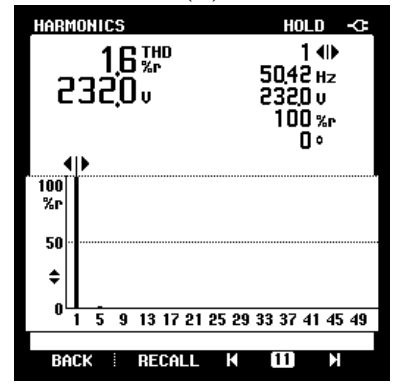

(c)

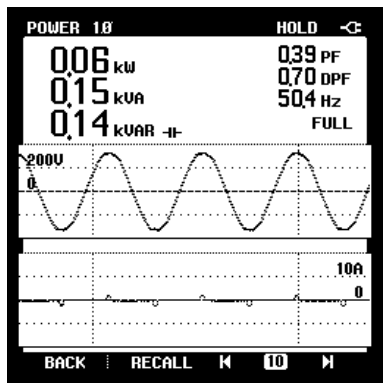

(b)

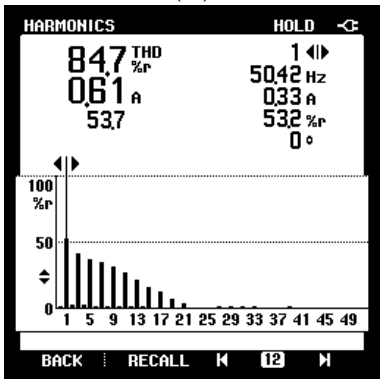

(d)
Fig. 3: SMPS load, (a) Voltage \& Current Waveforms, (b) Power Quantities, (c) $T H D_{v}$, (d) $T H D_{i}$

analysis readings, it is observed that $T H D_{v}$ for most SMPS loads is in the range of $(1.6 \%-3 \%)$, while the value of $T H D_{i}$ is nearly $51.8 \%-86.7 \%$ categorized high in producing harmonic. The large difference between measured values of $T H D_{v}$ and $T H D_{i}$ is due to the fact that an individual power electronic load does not have a significant effect on the input supply voltage, therefore, $T H D_{V}$ remains in the acceptable standard limit of $5 \%$, however, the input current waveform of most electronic loads is characterized by a pulsating current. The result is that such a waveform of input supply current contains a high level of harmonic distortion and therefore the value of $T H D_{i}$ is also high.

Individual harmonics and percentage $T H D$ value founded in the input supply current are crossing the limit as compared to international Standard. In view of the fact that current and power rating values of home-based electrical appliances devices are very low, it is understood that harmonic distortion effects of these appliances might not be harmful to the electrical power systems. Nevertheless, the cumulative effects of combined electrical appliances are too significant to be ignored.

\section{Simulation Model of SMPS Load}

It is observed that SMPS-based loads are rich in current harmonic distortion. Therefore, an equivalent model of SMPS load in MATLAB/Simulink is developed to analyze improvement in power quality 


\begin{tabular}{|c|c|c|c|c|c|c|c|c|c|c|c|c|}
\hline $\begin{array}{c}\text { Load } \\
\text { Types }\end{array}$ & $\begin{array}{c}\text { Electric } \\
\text { Appliances }\end{array}$ & ISV & ISC & VCF & $\mathrm{CCF}$ & $\begin{array}{c}\text { AP } \\
(\mathrm{kW})\end{array}$ & $\begin{array}{c}\text { ApP } \\
(\mathrm{kVA})\end{array}$ & $\begin{array}{c}\text { RP } \\
\text { (KVar) }\end{array}$ & DPF & $\mathbf{P F}$ & $\begin{array}{c}\text { THD } \\
(\%)\end{array}$ & $\begin{array}{c}\text { THD } \\
(\%)\end{array}$ \\
\hline \multirow{5}{*}{$\begin{array}{l}\text { Resistive } \\
\text { Load }\end{array}$} & $\begin{array}{l}\text { Electric } \\
\text { Iron }\end{array}$ & 221.2 & 42.82 & 1.4 & 1.4 & 9.50 & 9.51 & 0.44 & 1 & 1 & 2.0 & 1.8 \\
\hline & $\begin{array}{l}\text { Electric } \\
\text { Bulb }\end{array}$ & 235.1 & 4.33 & 1.3 & 1.3 & 1.02 & 1.02 & 0.05 & 1 & 1 & 1.8 & 1.8 \\
\hline & $\begin{array}{l}\text { Electrical } \\
\text { Heater }\end{array}$ & 229.9 & 16.50 & 1.4 & 1.3 & 3.79 & 3.79 & 0.17 & 1 & 1 & 2.1 & 2.2 \\
\hline & $\begin{array}{l}\text { Electric } \\
\text { Kettle }\end{array}$ & 220.5 & 59.6 & 1.4 & 1.3 & 13.0 & 13.0 & 0.4 & 1 & 1 & 2.3 & 2.1 \\
\hline & $\begin{array}{l}\text { Zero Watts } \\
\text { Bulb }\end{array}$ & 234.7 & 0.63 & 1.4 & 1.3 & 0.15 & 0.15 & 0.01 & 1 & 1 & 2.0 & 4.2 \\
\hline \multirow{7}{*}{$\begin{array}{l}\text { Inductive } \\
\text { Load }\end{array}$} & $\begin{array}{l}\text { Water Pump } \\
\text { Motor }\end{array}$ & 232.5 & 0.90 & 1.3 & 1.5 & 0.18 & 0.21 & 0.11 & 0.85 & 0.86 & 1.5 & 24.2 \\
\hline & $\begin{array}{l}\text { Juicer } \\
\text { Machine }\end{array}$ & 224.4 & 8.74 & 1.4 & 1.6 & 1.89 & 1.96 & 0.51 & 0.98 & 0.97 & 1.9 & 14.5 \\
\hline & $\begin{array}{l}\text { Pedestal } \\
\text { Fan }\end{array}$ & 221.5 & 6.24 & 1.4 & 1.4 & 1.36 & 1.40 & 0.34 & 0.97 & 0.97 & 1.9 & 4.5 \\
\hline & $\begin{array}{l}\text { Washing } \\
\text { Machine }\end{array}$ & 223.7 & 10.55 & 1.4 & 1.6 & 2.33 & 2.36 & 0.37 & 0.97 & 0.97 & 1.9 & 12.8 \\
\hline & $\begin{array}{l}\text { Drill } \\
\text { Machine }\end{array}$ & 237.7 & 11.26 & 1.3 & 1.1 & 2.58 & 2.60 & 0.36 & 0.97 & 0.91 & 1.9 & 6.2 \\
\hline & Refrigerator & 224.8 & 2.39 & 1.4 & 1.8 & 0.15 & 0.54 & 0.52 & 0.29 & 0.27 & 2.1 & 33.6 \\
\hline & $\begin{array}{l}\text { Mini Loud } \\
\text { Speaker }\end{array}$ & 239.5 & 0.68 & 1.4 & 1.6 & 0.12 & 0.16 & 0.11 & 0.73 & 0.72 & 2.1 & 42.1 \\
\hline \multirow{14}{*}{$\begin{array}{l}\text { Switch } \\
\text { Mode } \\
\text { Power } \\
\text { Supply } \\
\text { LOAD }\end{array}$} & $\begin{array}{l}\text { Personal } \\
\text { Computer }\end{array}$ & 238.9 & 0.61 & 1.3 & 3.3 & 0.06 & 0.15 & 0.14 & 0.70 & 0.39 & 1.6 & 84.7 \\
\hline & Laptop & 234.5 & 0.3 & 1.3 & 3.3 & 0.04 & 0.05 & 0.01 & 0.95 & 0.79 & 1.6 & 83.1 \\
\hline & LED TV & 224.3 & 2.47 & 1.4 & 3.1 & 0.29 & 0.55 & 0.47 & 0.99 & 0.53 & 2.1 & 83.8 \\
\hline & $\begin{array}{l}\text { Dish } \\
\text { Receiver }\end{array}$ & 226.4 & 0.32 & 1.4 & 5.5 & 0.04 & 0.07 & 0.06 & 0.99 & 0.57 & 2.2 & 86.2 \\
\hline & $\begin{array}{l}\text { Energy } \\
\text { Savor }\end{array}$ & 221.7 & 1.36 & 1.4 & 3.3 & 0.18 & 0.31 & 0.25 & 0.94 & 0.57 & 2.1 & 78.0 \\
\hline & UPS & 225.7 & 22.06 & 1.4 & 3.4 & 1.75 & 4.16 & 3.77 & 0.78 & 0.38 & 1.7 & 86.7 \\
\hline & $\begin{array}{l}\text { Charging } \\
\text { Fan }\end{array}$ & 233.9 & 0.42 & 1.3 & 2.3 & 0.09 & 0.10 & 0.04 & 0.89 & 0.81 & 2.3 & 55.8 \\
\hline & $\begin{array}{l}\text { Mobile } \\
\text { Charger }\end{array}$ & 231.5 & 0.53 & 1.4 & 3.4 & 0.06 & 0.19 & 0.18 & 0.34 & 0.24 & 3.0 & 86.4 \\
\hline & Printer & 238.9 & 2.21 & 1.4 & 2.3 & 0.01 & 0.02 & 0.02 & 0.24 & 0.15 & 2.0 & 51.8 \\
\hline & $\begin{array}{l}\text { Air } \\
\text { Conditioner }\end{array}$ & 235.2 & 71.1 & 1.3 & 2.2 & 16.7 & 16.7 & 0.90 & 0.80 & 0.9 & 1.9 & 68.5 \\
\hline & $\begin{array}{l}\text { Microwave } \\
\text { Oven }\end{array}$ & 233.3 & 0.87 & 1.3 & 1.3 & 0.20 & 0.20 & 0.01 & 0.99 & 0.95 & 1.8 & 33.3 \\
\hline & Television & 233.1 & 3.20 & 1.3 & 2.1 & 0.47 & 0.77 & 0.61 & 0.99 & 0.61 & 2.1 & 78.0 \\
\hline & $\begin{array}{l}\text { Charging } \\
\text { Torch }\end{array}$ & 234.9 & 0.78 & 1.3 & 2.6 & 0.01 & 0.19 & 0.19 & 0.09 & 0.07 & 1.9 & 30.5 \\
\hline & $\begin{array}{l}\text { Hair } \\
\text { Dryer }\end{array}$ & 235.6 & 28.09 & 1.4 & 1.7 & 6.03 & $6.65 \mathrm{k}$ & $2.79 \mathrm{k}$ & 0.91 & 0.90 & 2.2 & 40.5 \\
\hline
\end{tabular}

TABLE 1: Power quality analyzer measurement results for individual electric

using the passive filter. The input supply voltage and current waveforms before connecting the passive filter are shown in Figure 4. FFT analysis of input supply voltage and input supply current waveforms shows the total harmonic distortion in the input supply voltage is $1.493 \%$ which is within the acceptable limit. Whereas, in the input supply current waveform, the total harmonic distortion is $85.42 \%$. The leading harmonic components in input supply current waveform are no- ticed as 3rd, 5th, 7th and 9th order harmonics. Hence, these harmonic components mitigate the improvement in power quality.

\subsection{Design \& Implementation of Passive Filter}

Conventionally for harmonic control and reactive power compensation, the most commonly used solution is the passive filter. Passive filters are designed using passive components such as capacitor, inductor 
and resistor. Passive filters are of two types namely shunt and series passive filters for elimination of current and voltage harmonics respectively. The shunt passive filter has a low cost and is capable of delivering reactive power at a fundamental frequency which is the reason why this type of filter is most suitable for practical use for harmonic filters [25].

In this work, two double-tuned shunt filters have been designed to remove the 3rd and 5th order harmonics and 7th and 9th order current harmonics.

\subsection{Double Tuned Filter}

The double-tuned filter (DTF) is used to reduce two harmonic components at the same time. The basic configuration of DTF is shown in Figure 5. It consists of a series resonance circuit ( $L_{d l}$ and $C_{d 1}$ parameters) and a parallel resonance circuit $\left(L_{d 2}\right.$ and $C_{d 2}$ parameters). For designing DTF, system voltage $V$ (volt), reactive power $Q$ (Var), the fundamental frequency $(f=50 \mathrm{~Hz})$ and angular frequency $(w=2 \pi f=314$ $\mathrm{rad})$, the identified tuned frequencies relative to the order of harmonics $w_{1}$ and $w_{2}$ (rad), series resonant frequency $w_{s}$ and parallel resonant frequency $w_{p}$ are interconnected as in [26].

$$
\begin{gathered}
X_{C}=\frac{V_{S}^{2}}{Q} \\
C=\frac{1}{2 \pi f X_{C}} \\
w_{1} w_{2}=w_{s} w_{p}
\end{gathered}
$$

The $c_{d 1}(\mu F)$ parameter can be obtained as

$$
c_{d 1}=c_{1}+c_{2}
$$

The $c_{1}(\mu F)$ and $c_{2}(\mu F)$ are the capacitances for the two separate single tuned passive filters whose values are equal such that $c_{1}=c_{2}$. The $L d 1(m H)$ parameter value can be determined from

$$
L_{d 1}=\frac{1}{C_{1} W_{1}^{2}+C_{2} W_{2}^{2}}
$$

The $w_{s}$ parameter is calculated as,

$$
w_{s}=\sqrt{\frac{1}{L_{d 1} C_{d 1}}}
$$

After putting values of $w_{1}, w_{2}, w_{s}$ in equation (8), the value of $w_{p}$ parameter can be calculated. The $L_{d 2}$ parameter is determined as follows.

$$
L_{d 2}=\frac{\left(1-\frac{W_{1}^{2}}{W_{s}^{2}}\right)\left(1-\frac{W_{1}^{2}}{\left(W_{P}^{2}\right.}\right)}{\left(C_{d 1} W_{1}^{2}\right)}
$$

\begin{tabular}{|l|l|l|}
\hline S.No. & Parameters & Magnitudes \\
\hline 1 & Vs $(\mathrm{V})$ & 220 \\
\hline 2 & $\mathrm{~F}(\mathrm{~Hz})$ & 50 \\
\hline 3 & Rsys $(\Omega)$ & 2 \\
\hline 4 & Lsys $(\mathrm{mH})$ & 2 \\
\hline 5 & RSMPS $(\Omega)$ & 1 \\
\hline 6 & LSMPS $(\mathrm{mH})$ & 1 \\
\hline 7 & Vf $(\mathrm{v})$ & 0.8 \\
\hline 8 & $\operatorname{Cdc}(\mu \mathrm{F})$ & 15 \\
\hline 9 & $\operatorname{RL~}(\Omega)$ & 500 \\
\hline
\end{tabular}

TABLE 2: Parameters used for simulation

\begin{tabular}{|l|l|}
\hline Index & Magnitudes \\
\hline VS (V) & 219.2 \\
\hline $\mathrm{I}(\mathrm{A})$ & 0.8282 \\
\hline $\mathrm{S}(\mathrm{VA})$ & 181.5 \\
\hline $\mathrm{DPF}(\cos \phi)$ & 0.846 \\
\hline$T H D_{V}(\%)$ & 1.493 \\
\hline$T H D_{i}(\%)$ & 85.42 \\
\hline
\end{tabular}

TABLE 3: Obtained results of the simulation model

Lastly, parameter $C_{d 2}$ is given by,

$$
C_{d 2}=\frac{1}{L_{d 1} W_{p}^{2}}
$$

The DTF parameter values are calculated from equation (6) to equation (13). The MATLAB/Simulink model of SMPS load with DTPF is shown in Figure 6. The parameters used for the Simulink model are shown in Table 2 and the obtained results of the simulation carried out are given in Table 3 . The two designed DTF for 3rd \& 5th and (7th \& 9th) order harmonics are shown in Table 4. It can be observed that prior to compensation, the input supply current is a nonsinusoidal waveform, and after compensation by the

\begin{tabular}{|l|l|l|l|}
\hline $\begin{array}{l}\text { Tuned } \\
\text { Harmonics }\end{array}$ & $\begin{array}{l}\text { Tuned } \\
\text { Frequencies } \\
(\mathbf{r a d} / \mathbf{s e c})\end{array}$ & $\begin{array}{l}\text { Capacitance } \\
(\mu F)\end{array}$ & $\begin{array}{l}\text { Inductance } \\
(\mathbf{m H})\end{array}$ \\
\hline \multirow{3}{*}{ 3rd and 5th } & $w_{1}=942$ & $\mathrm{C}$ branch $=22 \mu F$ & $L_{d 1}=13.5$ \\
& $w_{2}=1570$ & $C_{d 1}=44 \mu F$ & $L_{d 2}=3.8$ \\
& $w_{s}=1294.6$ & $C_{d 2}=198.6$ & \\
\hline & $w_{p}=1142.3$ & $\mathrm{C} \mathrm{branch=22 \mu F}$ & $L_{d 1}=3.5$ \\
7 th and 9th & $w_{1}=2198$ & $w_{2}=2826$ & $\mathrm{Cd} 1=44 \mu F$ \\
& $w_{s}=2531.5$ & $\mathrm{Cd} 2=726.1$ & $L_{d 2}=0.22$ \\
& $w_{p}=2453.6$ & & \\
\hline
\end{tabular}

\begin{tabular}{|l|l|l|l|l|}
\hline $\begin{array}{l}\text { Filter } \\
\text { Installation }\end{array}$ & \% THDV & \% THDI & PF & TPF \\
\hline No Filter & 1.493 & 85.43 & 0.846 & 0.631 \\
\hline $\begin{array}{l}\text { Double Tuned } \\
\text { Passive Filter }\end{array}$ & 1.031 & 3.617 & 0.862 & 0.862 \\
\hline
\end{tabular}

TABLE 4: Obtained results without and with filters 


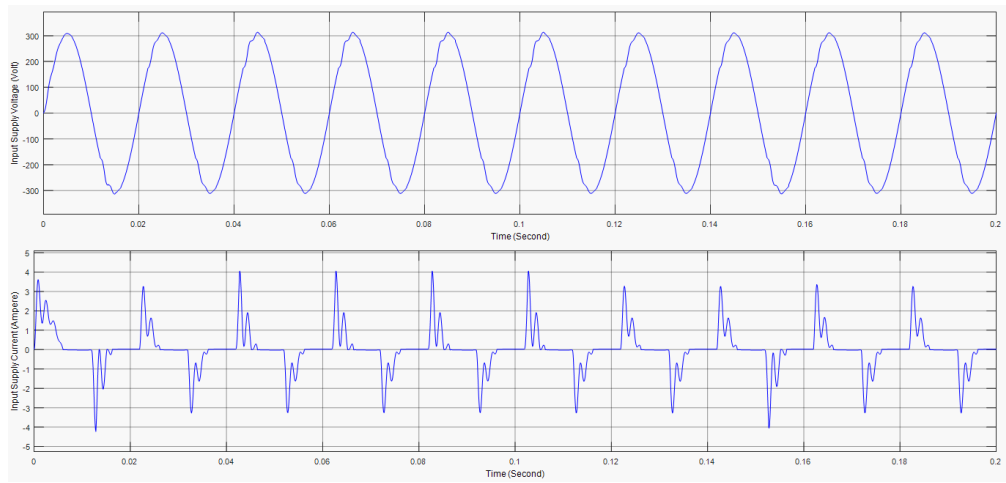

Fig. 4: Input voltage and current waveforms

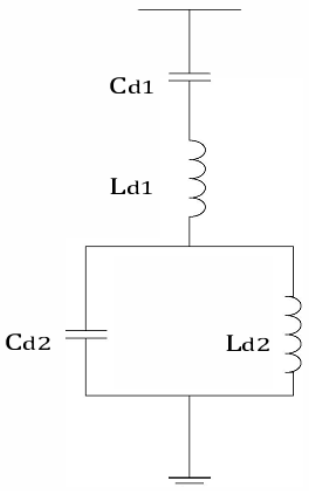

Fig. 5: Double tuned passive filter arrangement

double-tuned passive filter, as shown in Figure 7, the source current becomes almost sinusoidal. In source current, the value of \%THD reduces to $3.617 \%$ with DTPF, and now the input source or supply current $\%$ THD is within the requirement of the international standard limits. As a result of the installation of DTPF, the DPF increased from 0.846 to 0.862 , and TPF increased from 0.631 to 0.862 , as shown in Table 5 . Hence the proposed passive filter provides us not only an efficient reduction in harmonic distortion, but also an improvement of TPF which is a requirement in the case of non-linear power electronic load.

\section{Conclusion}

It is concluded that the electrical appliances used for domestic purposes can be considered as the chief sources of harmonics. This paper was intended to identify the harmonics generated in the electrical system due to various electrical appliances, and helps to identify the levels of harmonic voltages and currents. It is observed from the experimental results that SMPSbased electrical appliances have harmful effects. To design a more efficient solution, this work contributes knowledge to the designer and researchers to overcome poor power quality which is mostly caused by home appliances. Even though home-based electric appliances are low-power devices, the cumulative effect created from the huge number of small harmonic sources can be substantial. It is shown that due to the existence of harmonics, the power factor is reduced. The performed simulated examination shows the effectiveness of DTF for harmonic removal. From the simulation results, it is evident that in reducing current harmonic distortion, the DTF is effective and input supply or source current distortion is well satisfied within the harmonic limit requirement of international standard. Once the harmonics are under the specified limit, the associated power losses disappear and both electrical appliances and the systems will run smoothly and efficiently.

\section{References}

[1] J. Arrillaga and N. R. Watson, "Power System Harmonics," John Wiley \& Sons, Ltd., West Sussex, England, 2003.

[2] H. Farooq, C. Zhou and M. E. Farrag, "Analyzing the Harmonic Distortion in a Distribution System Caused by the Nonlinear Residential Loads," International Journal of Smart Grid and Clean Energy, Vol. 2, No. 1, pp.46-51, 2013.

[3] H. E. Mazin, E. E. Nino, W. Xuand J. Yong,"A Study on the Harmonic Contributions of Residential Loads," IEEE Transactions on Power Delivery, Vol. 26, No. 3, pp. 15921599, 2011.

[4] J. Meyer, P. Schegner, K. Heidenreich, "Harmonic Summation Effects of Modern Lamp Technologies and Small Electronic Household Equipment, 21st International Conference on Electricity Distribution, Frankfurt, pp.1-4, 2011.

[5] Don O. Koval and C. Carter,"Power Quality Characteristics of Computer Loads, IEEE Transactions on Indus-try Applications, Vol. 33, No. 3, pp.613-621, 1997.

[6] S.G.Bankar, A.R.Bhedarker, A.P.Bhurbhure and B.S.Rakhonde, "Impact of nonlinear load on power quality", International Journal of Recent Innovation \& Trends Computation. Vol.5, No.2, pp.223-226, 2017.

[7] R. Rodrigues, E. Wilson, M. Malcolm and A. Souza, "Impact of appliances harmonic content in microgrid environments," IEEE PES Innovative Smart Grid Technologies Latin America, 2015. 


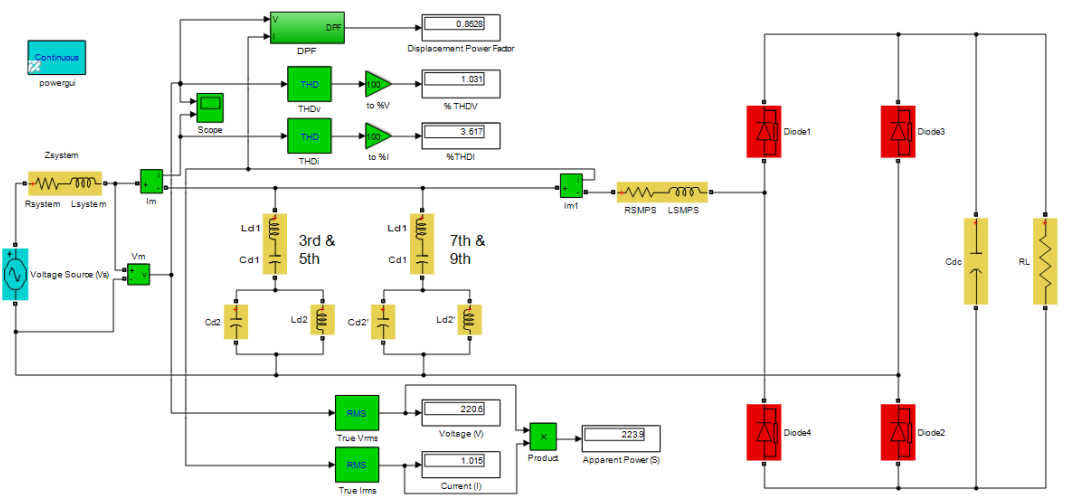

Fig. 6: Simulink model of SMPS load with DTPF

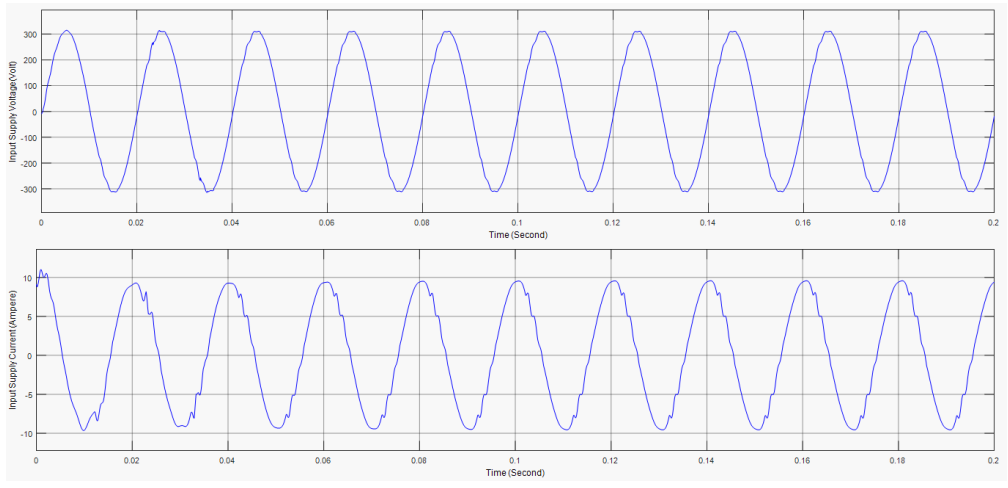

Fig. 7: Input voltage and current waveforms with DTPF

[8] U. Muhammad, S. Muhammad, S. Abdul Sattar, A. Munwar,"Harmonics measurement in computer laboratory and design of passive harmonic filter using MATLAB", Int. J. Adv. Comput.Sci. Appl. Vol. 12, pp. 240-247, 2017.

[9] N. Karuna, W. Abhay, "Hardware Implementation of StepSwitched SVCs to Correct Power factor and Mitigate Harmonics for Large DC Variable Loads," Journal of Institution of Engineer series B, Vol. 101, No. 6, pp.777-789, 2020.

[10] A. Mohammad, H. Sillas, "Harmonics Mitigation Based on the Minimization of Non-Linearity Current in a Pow-er System," designs, MDPI, Vol. 3, No. 29, 2019.

[11] H. Mageed, A.S. Nada, S.A. Zaid, R.S. Salah, "Effects of Waveforms Distortion for Household Appliances on Power Quality," MAPAN-Journal of Metrology Society of India, Vol. 34, No. 4, pp.559-572, 2019.

[12] S. Karthik, T. Shantam, "Power factor correction using capacitors \& filters," International Journal of Engineering \& Technology, Vol. 7, No. 12, 2018.

[13] V. Szücs, A. Fodor, A. Göllei and P. Görbe "Examination of Nonlinear Distortion of IT Power Supplies in Low Voltage Grid from the Current Quality Point of View," ACTA Physica Polonica A, Vol. 134, pp.307-310, 2018.

[14] C. Kumarshanu, R. Sagar, P. Sachin, P. Abhishek, "Reactive Power Management Using TSC-TCR," International Research Journal of Engineering and Technology, Vol. 5, No. 4, pp. 1427-1431, 2018.

[15] M.Z. Radzi, M.M. Ismail,"Observatory case study on total harmonic distortion in current at laboratory and office building," Journal of Physics: Conference Series, IOP Publishing, pp.1-9, 2019.

[16] S.A. Sahidaini, "Electrical Power Quality Improvement through Modeling and Optimization of Passive Harmonic Filter," International Journal of Engineering Re-search \& Technology (IJERT), Vol. 7, No. 10, pp.103-110, 2018.

[17] T. Tanes, L. Sunisha, "Design of Experimental Learning Module on Passive Harmonic Filter for Variable Speed Drive," IEEE International conference on industrial Engineering and applications, pp.33-36,2019.

[18] Y.K. Haur, T.J. Son, L.K. Yun and W.J. Raymond, "Design of Single-Tuned Passive Harmonic Filter to Meet Ieee519 Standard By Means of Quality-Factor Manipulations," International Journal of Advanced Science and Technology, Vol. 29, No. 1, pp. 1364- 1379,2020.

[19] S. Michael, "The influence of non-linear loads on the power quality of the New-Zland low voltage electrical residential power distribution network," Master Thesis, Massey University, Manawatu, 2012.

[20] F.M. Arrabal-Campos, F.G. Montoya, R.Banos,J. Martınez-Lao and A. Alcayde, "Simulation of power quality disturbances through the wavelet transform," Conference on harmonics and quality of power, 2018.

[21] IEEE Std 1459-2010, "Definitions for the Measurement of Electric Power Quantities Under Sinusoidal, Nonsinusoidal, Balanced, or Unbalanced Conditions," February 2010 (Revision of IEEE Std 1459-2000).

[22] A. Kamenka, "Harmonic distortion and Power Quality indices in electric power systems," Schaffner Group, 2014.

[23] A. Gobbi, "Understanding Power Factor and Input Current Harmonics in Switched Mode Power Supplies," Whitepaper, TDI power, 2009.

[24] J.A. Pomilio , S. M. Deckmann, "Characterization and Compensation of Harmonics and Reactive Power of Res- 
idential and Commercial Loads," IEEE Transactions on Power Delivery, Vol. 22, No. 2, pp. 1049-1055, 2007

[25] R.B. Ambatkar, A.P. Bagde, R.G. Bhure, and B.S. Rakhonde, "Study OF Different Passive filter- A review," International Research Journal of Engineering and Technology (IRJET), Vol. 4, No. 1, pp.1437-1439. 2017.

[26] A. Baitha, and N. Gupta, "A Comparative Analysis of Passive Filters for Power Quality Improvement," IEEE International Conference on Technological Advancements in Power \& Energy, pp.327-332, 2015. 